1 Fundação Oswaldo Cruz (Fiocruz), Escola Nacional de Saúde Pública Sergio Arouca (Ensp) Departamento de Ciências Sociais - Rio de Janeiro (RJ), Brasil.

mirna@ensp.fiocruz.br

2 Fundação Oswaldo Cruz (Fiocruz), Escola Nacional de Saúde Pública Sergio Arouca (Ensp) Departamento de Ciências Sociais - Rio de Janeiro (RJ), Brasil.

engstorm@ensp.fiocruz.br

${ }^{3}$ Fundação Oswaldo Cruz (Fiocruz), Escola Nacional de Saúde Pública Sergio Arouca (Ensp),

Departamento de Ciências

Sociais - Rio de Janeiro

(RJ), Brasil.

ribeiro@ensp.fiocruz.br

\section{Revisão sistemática da literatura sobre crack: análise do seu uso prejudicial nas dimensões individual e contextual}

\author{
Systematic review of the literature on crack: analysis of its harmful \\ use in the individual and contextual dimensions
}

Mirna Barros Teixeira', Elyne Montenegro Engstrom², José Mendes Ribeiro ${ }^{\mathbf{3}}$

RESUMO Este artigo visa investigar como se conformam, no Brasil e internacionalmente, as abordagens ao uso prejudicial do crack e outras drogas. Foi realizada uma revisão crítica da literatura acerca do padrão de consumo do crack e os fatores a ele relacionados com busca sistemática em bases eletrônicas no período de 2010 a 2016. Foram analisados 37 artigos por autor, ano, país do estudo, metodologia; padrão de consumo de crack e fatores individuais e contextuais relativos a esse uso. Conclui-se que a abordagem ao uso de drogas deve estar focada na perspectiva da redução de danos, na promoção da autonomia e dos direitos humanos, e não na utopia de eliminação do consumo e da produção de drogas.

PALAVRAS-CHAVE Cocaína crack. Redução de danos. Políticas públicas. Drogas ilícitas.

ABSTRACT This article investigates how the approaches towards the harmful use of crack cocaine and other drugs are conformed in Brazil and worldwide. A critical revision of the literature has been made regarding the pattern of consumption of crack cocaine and its related factors through a systematic search in scientific publications electronic data bases between 2010 and 2016. 37 articles have been analyzed by author, year, country of the study, and methodology; crack cocaine consumption pattern, individual and contextual factors related to this consumption. The conclusion was that the approach towards the use of drugs should be focused on damage reduction perspective, promotion of autonomy and human rights, and not on the utopia of eliminating consumption and drugs production.

KEYWORDS Crack cocaine. Harm reduction. Public policies. Street drugs. 


\section{Introdução}

Por muitas décadas e em vários países, as políticas e ações voltadas ao uso de drogas eram focadas principalmente pelas lentes da justiça criminal. No entanto, é preciso considerar o uso prejudicial de drogas como um problema de saúde pública por sua magnitude elevada e crescente, por sua natureza multifatorial e pelas repercussões na saúde e na vida das pessoas, famílias e comunidades. Especialmente no século XXI, consolidam-se novos paradigmas que fortalecem o protagonismo da abordagem pela saúde pública, desenvolvendo-se modelos voltados para atenção integral, psicossocial e com estratégias para a Redução de Danos (RD) devido ao uso prejudicial de drogas. Essa nova forma de olhar o problema vem gerando tensões no campo da saúde, em suas diversas abordagens do cuidado ao usuário de drogas, assim como disputas com outros setores públicos e da sociedade que historicamente advogam ações coercitivas de afastamento e isolamento, na visão de um 'fictício mundo sem drogas'.

Estima-se que 246 milhões de pessoas usem drogas mundialmente, em uma prevalência global de $5,2 \%$, em que um entre dez usuários sofrerá de dependência da droga (cerca de 27 milhões de pessoas), sendo metade usuários de drogas injetáveis e boa parcela com HIV (Vírus da Imunodeficiência Humana) (UNODC, 2015). O relatório mundial sobre drogas estimou 187.100 mortes relacionadas com o uso prejudicial de drogas (UNODC, 2015). Já um estudo brasileiro recente fez uma estimativa de usuários de crack (UC) regulares e/ou similares em 370 mil pessoas, o que corresponde a $35 \%$ dos consumidores de drogas nas capitais do País (BASTOS; BERTONI, 2014).

Entre os vários tipos de Substâncias Psicoativas (SPA) existentes, o artigo tem como foco o uso prejudicial do crack, pelo uso disseminado e crescente no Brasil a partir dos anos 1990, pelo destaque na mídia e pela forte associação a aspectos de vulnerabilidade social (NAPPO; SANCHEZ; OLIVEIRA, 2011).
O termo 'crack' é uma onomatopeia e se refere ao som produzido durante a sua produção;

cocaína e bicarbonato de sódio são dissolvidos em água e aquecidos até que se formem cristais de cocaína que produzem um característico estalido (crack). (HART, 2014, P. 163).

O seu surgimento no Brasil foi detectado por agentes redutores de danos que trabalhavam com drogas injetáveis. O uso do crack é menos significante se comparado à distribuição e uso de vários outros tipos de drogas entre a população brasileira. No entanto, quando se foca em determinados segmentos da população mais vulneráveis, como a População em Situação de Rua (PSR), ele assume maior relevância (BRASIL, 2014).

Para estudar crack e outras drogas, partiu-se do pressuposto básico de que a droga sempre existiu na humanidade, que uma sociedade livre de drogas é uma falácia e que, portanto, seu uso problemático não diz respeito a todas as pessoas que as consomem (ESCOHOTADO, 1996). Segundo Hart (2014), apenas $25 \%$ das pessoas que experimentam qualquer tipo de SPA, das consideradas mais leves até as mais estigmatizadas como crack e heroína, fazem uso prejudicial. Na pesquisa sobre o perfil brasileiro dos UC, observou-se que a maioria consumia outras substâncias lícitas como álcool e tabaco, sendo o crack apenas uma das drogas consumidas em um amplo portfólio de SPA, sendo por isso denominados poliusuários. Outro achado importante é que embora nem toda população de rua seja usuário de drogas, um percentual relevante, cerca de $40 \%$ que se encontravam em situação de rua no momento em que foi realizada a pesquisa usavam crack. Bastos e Bertoni (2014) relataram ser o perfil geral dos UC composto na sua maioria de jovens, negros, de baixa escolaridade, vivendo em situação de rua e sem emprego fixo, apresentando-se como um grupo de extrema vulnerabilidade social. Assim, a compreensão do 
uso prejudicial de crack como um problema social é fundamental para pensar em estratégias de intervenção.

A vulnerabilidade é um conceito aplicável a qualquer dano ou condição de interesse para a saúde pública como, por exemplo, o uso prejudicial de crack e outras drogas. Reforça-se aqui que a abordagem da prevenção ao uso de drogas não depende apenas da informação acrescida da vontade do indivíduo, mas de uma série de fatores individuais, coletivos e contextuais, sendo a vulnerabilidade definida como

[...] a chance de exposição das pessoas ao adoecimento como a resultante de um conjunto de aspectos não apenas individuais, mas coletivos, contextuais, que acarretam maior suscetibilidade à infecção e ao adoecimento e, de modo inseparável, maior ou menor disponibilidade de recursos de todas as ordens para se proteger de ambos. (AYRES ET AL., 2005, P. 123).

No campo do cuidado às pessoas em uso prejudicial de drogas, é importante investir em ações redutoras de vulnerabilidades a esse uso, entendendo que essas pessoas não são vulneráveis, mas estão vulneráveis a algo, em algum grau, e em um tempo e espaço definido; ou seja, a vulnerabilidade é resultante da dinâmica relação entre os componentes individuais e SOciais (AYRES, 2002; SODELLI, 2015). Nesse sentido, as intervenções e políticas públicas devem levar em conta a vulnerabilidade associada ao uso prejudicial de crack e outras drogas.

Este artigo aborda os fatores associados ao uso prejudicial de crack partindo de um modelo multidimensional de drogas (ZINBERG, 1984) que reforça a tese das drogas como um problema complexo, em que é preciso considerar três importantes dimensões de análise para sua intervenção: as características individuais (o indivíduo); os diferentes efeitos e usos ou padrão de consumo de SPA (a droga) e os fatores sociais envolvidos nesse consumo (o contexto). Segundo Fiore (2013, P. 6),

[...] não há substância nem um indivíduo como elementos universais e objetivos, mas há contextos sociais e culturais diferentes, de substâncias diferentes e realizada por indivíduos diferentes e, sem a devida atenção a essas diferenças não é possível se compreender o fenômeno.

Dessa forma, diante da complexidade da discussão sobre drogas, objetiva-se, neste artigo, analisar a literatura brasileira e internacional acerca do padrão de uso do crack, suas especificidades e os fatores individuais e contextuais envolvidos nesse uso, de modo a compreender os fatores de vulnerabilidade social associados e refletir acerca das estratégias de intervenção em saúde pública.

\section{Metodologia}

Trata-se de uma revisão sistemática da literatura sobre crack, que responde a uma questão norteadora usando métodos sistemáticos e explícitos para selecionar e avaliar pesquisas relevantes ao tema (SAMPAIO; MANCINI, 2007). Realizou-se busca em bases eletrônicas de publicações científicas, sendo identificadas as seguintes: Scopus; Public/Publisher Medline (PubMed); Scientific Electronic Library Online (SciELO), Web of Science; Elsevier e Medical Literature Analysis and Retrieval System Online (Medline). Utilizou-se o Portal de Periódicos Capes (Coordenação de Aperfeiçoamento de Pessoal de Nível Superior) como fonte de referências, uma vez que ele oferece acesso a textos completos disponíveis em mais de 37 mil publicações periódicas, internacionais e nacionais e a diversas bases de dados. Como período de busca, utilizou-se os últimos seis anos de produção, de janeiro de 2010 a junho de 2016. Optou-se por tal período porque o debate sobre crack se ampliou nos últimos anos com o surgimento de novas políticas públicas como o Programa Crack é Possível Vencer (BRASIL, 2010). Cabe destacar, ainda, que já foi realizado um estudo similar de revisão sistemática sobre o tema pelos autores Zanotto e Buchele (2013) no período anterior de 2000 a 2010. Os descritores 
e termos MesH consultados nas buscas foram: 'Crack users'; 'crack cocaine'; 'crack addiction' no campo 'título e/ou abstract'. Em seguida, foi feita uma combinação por meio do conector boleano and com 'Policy'; 'Public Policy'; 'Public Health', no campo 'Título e/ou abstract' + 'keywords'. Foram eleitos artigos nos idiomas inglês, espanhol e português. Foram utilizados como critério de inclusão para seleção dos artigos: estudos que abordassem UC, publicados nas bases de dados no período definido e na língua portuguesa, inglesa ou espanhola. Já como critérios de exclusão intencionais utilizou-se: os estudos experimentais, os estudos que não investigaram UC, os estudos farmacológicos e os estudos que abordaram outras drogas que não especificamente o crack. Para definição dos artigos selecionados, foram feitas a leitura dos resumos e dos artigos completos por dois pesquisadores. Foi aplicado o protocolo AMSTAR (Assessement the Methodological Quality of Systematic Reviews) (SHEA ET AL., 2007) com alcance de 9 itens dentro dos 11 solicitados (apenas os itens 'não acesso a literatura cinzenta' e o 'não realização de teste de homogeneidade' não se aplicaram a esse tipo de revisão). A síntese do resultado da busca realizada nas bases pesquisadas se encontra sistematizada no fluxograma (figura 1). Ao se iniciar a leitura completa dos artigos, observou-se que 78 deles não abordavam diretamente estudos com usuários de crack, sendo, portanto, excluídos do estudo, ficando, assim, a análise crítica de 37 artigos completos.

Figura 1. Fluxograma

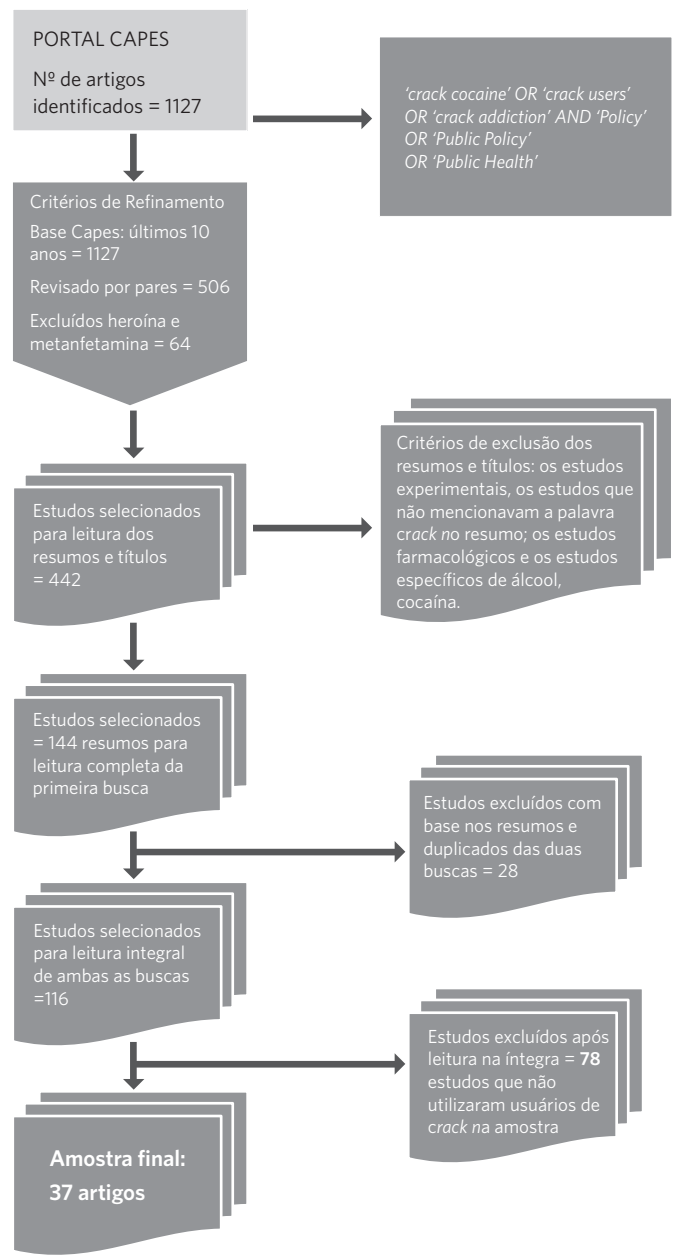


$\mathrm{Na}$ análise dos artigos, dois eixos temáticos foram criados como categorias emergentes: 1. Características do uso prejudicial de crack; 2. Fatores individuais e sociais associados ao uso prejudicial de crack. Cada artigo foi analisado segundo esses eixos, o ano de publicação e o país de estudo, sistematizados no quadro 1 .

\section{Resultados}

A distribuição temporal das 37 publicações analisadas foi a seguinte: 6 artigos (2010); 9 (2011); 5 (2012); 4 (2013); 7 (2014) e 6 (2015). No que se refere aos locais do estudo, 11 foram do Canadá, 19 do Brasil, 2 dos Estados Unidos, 2 de países europeus e 1 do México. Sobre o desenho, 21 foram estudos epidemiológicos (ensaio de campo=1; coorte $=5$ e inquérito=15); 13 utilizaram metodologia qualitativa e 3 estudos adotaram ambas as metodologias (inquéritos e pesquisa social) (quadro 1). Sobre a seleção dos participantes, 15 estudos foram de base comunitária ou populacional, 13 estudos fizeram seleção a partir de serviços de saúde ou sociais e 2 estudos incluíram participantes de ambas as localizações. Destaca-se que 6 estudos incluíram em seu universo de estudo, de forma exclusiva ou complementar a outros grupos, PSR. Apenas 1 estudo foi realizado exclusivamente em gestante UC. A grande maioria dos estudos incluiu pessoas de ambos os sexos; 6 incluíram apenas homens e 3 apenas mulheres. A faixa etária dos participantes foi principalmente composta por adultos jovens (entre 18 e 50 anos).

\begin{tabular}{|c|c|c|c|}
\hline $\begin{array}{c}\text { AUTOR } \\
\text { ANO } \\
\text { PAÍS, ESTADO }\end{array}$ & $\begin{array}{c}\text { METODOLOGIA: } \\
\text { Método Quanti/qualitativo, misto } \\
\text { População estudada (n, sexo, idade) } \\
\text { Critério de inclusão, } \\
\text { Base comunitária/serviços }\end{array}$ & $\begin{array}{c}\text { Eixo 1: } \\
\text { Padrão de consumo de crack }\end{array}$ & $\begin{array}{l}\text { Eixo 2: } \\
\text { Fatores individuais e contextuais (sociais) } \\
\text { relacionados ao uso de crack }\end{array}$ \\
\hline $\begin{array}{l}\text { WERB et al. } \\
\text { (2010) } \\
\text { Canadá, Vancouver }\end{array}$ & $\begin{array}{l}\text { Quantitativo (quanti), coorte } \\
\text { Base comunitária } \\
\mathrm{N}=1603 \text { usuários de crack (UC) em } \\
\text { situação de rua } \\
\text { Ambos os sexos. }\end{array}$ & Poliusuário & $\begin{array}{l}\text { População em Situação de Rua (PSR)/ } \\
\text { moradia instável } \\
\text { Prostituição }\end{array}$ \\
\hline $\begin{array}{l}\text { PAQUETTE et al. } \\
\text { (2010) } \\
\text { Canadá, Montreal }\end{array}$ & $\begin{array}{l}\text { Quanti, conveniência } \\
\text { Base comunitária } \\
N=203 \text { Jovens UC em situação de } \\
\text { rua } \\
\text { Média de } 19 \text { anos } \\
\text { Ambos os sexos. }\end{array}$ & $\begin{array}{l}\text { Poliusuário (cocaína) } \\
\text { Idade de início de uso do crack: jovem }\end{array}$ & $\begin{array}{l}\text { PSR } \\
\text { Contexto familiar conturbado (história } \\
\text { familiar de uso de SPA) }\end{array}$ \\
\hline $\begin{array}{l}\text { FICSHER et al. } \\
\text { (2010) } \\
\text { Canadá, British } \\
\text { Columbia }\end{array}$ & $\begin{array}{l}\text { Misto: Quanti e Qualitativo (quali) } \\
\text { N=148 UC Atendidos em centros } \\
\text { comunitários socais e de saúde }\end{array}$ & $\begin{array}{l}\text { Poliusuário (álcool, maconha e opióides) } \\
\text { Compartilhamento de apetrechos } \\
\text { Uso em cachimbos }\end{array}$ & $\begin{array}{l}\text { PSR/moradia instável } \\
\text { Baixa renda } \\
\text { Práticas ilícitas } \\
\text { Comprometimento no estado de saúde }\end{array}$ \\
\hline $\begin{array}{l}\text { OLIVEIRA; PONCE; } \\
\text { NAPPO } \\
\text { (2010) } \\
\text { Espanha, Barcelona }\end{array}$ & $\begin{array}{l}\text { Quali, etnografia, } \\
N=30 \text { UC na maioria homens; } \\
\text { Média entre } 20 \text { e } 40 \text { anos } \\
\text { Ambos os sexos }\end{array}$ & $\begin{array}{l}\text { Poliusuário (álcool, heroína, opióides, } \\
\text { metadona e ansiolítico) } \\
\text { Baixo custo da droga } \\
\text { Uso em cachimbos ou canudos } \\
\text { Padrão de uso compulsivo } \\
\text { Efeitos da droga: fases prazerosa, desa- } \\
\text { gradável, fissura, depressão e alucinação }\end{array}$ & $\begin{array}{l}\text { Baixa escolaridade } \\
\text { Desemprego }\end{array}$ \\
\hline
\end{tabular}




\begin{tabular}{|c|c|c|c|}
\hline \multicolumn{4}{|l|}{ Quadro 1. (cont.) } \\
\hline $\begin{array}{l}\text { ROTHERDAM- } \\
\text {-BORUS et al. } \\
\frac{(2010)}{\text { Estados Unidos, Los }} \\
\text { Angeles }\end{array}$ & $\begin{array}{l}\text { Quanti, coorte } \\
\text { N= } 875 \text { inicial e } 425 \text { no final } \\
\text { UC em situação de rua inscritos em } \\
\text { programas de Redução de Danos (RD) } \\
\text { Ambos os sexos }\end{array}$ & $\begin{array}{l}\text { Compartilhamento de apetrechos } \\
\text { Padrão de uso compulsivo }\end{array}$ & Comportamento de risco sexual \\
\hline $\begin{array}{l}\text { RIBEIRO; } \\
\text { SANCHEZ; NAPPO } \\
\text { (2010) } \\
\text { Brasil, São Paulo }\end{array}$ & $\begin{array}{l}\text { Quali, análise temática } \\
N=28 \cup C\end{array}$ & $\begin{array}{l}\text { Poliusuário (maconha e álcool) } \\
\text { Padrão de uso compulsivo } \\
\text { Tempo de uso durante a vida > } 11 \text { anos } \\
\text { Uso coletivo (grupal) como fator protetor } \\
\text { e em ambiente mais protegido } \\
\text { Efeitos da droga (Fissura, paranoia) } \\
\text { Overdose }\end{array}$ & $\begin{array}{l}\text { Comportamento de risco sexual } \\
\text { Desemprego } \\
\text { Prostituição } \\
\text { Práticas ilícitas }\end{array}$ \\
\hline $\begin{array}{l}\text { IVSINS et al. } \\
\text { (2011) } \\
\text { Canadá, Vitoria }\end{array}$ & $\begin{array}{l}\text { Quali, entrevista semiestruturada } \\
\text { Base comunitária } \\
\text { N = } 31 \text { UC selecionados a partir de } \\
\text { Programa de Distribuição de Kits uso } \\
\text { seguro } \\
\text { Ambos os sexos }\end{array}$ & $\begin{array}{l}\text { Poliusuário } \\
\text { Compartilhamento de apetrechos }\end{array}$ & $\begin{array}{l}\text { Relação com a marginalidade; } \\
\text { Comprometimento do estado de saúde } \\
\text { (descuido no autocuidado) } \\
\text { Percepção de insegurança pessoal e } \\
\text { comunitária }\end{array}$ \\
\hline $\begin{array}{l}\text { MALCHY et al. } \\
\text { (2011) } \\
\text { Canadá, Vancouver }\end{array}$ & $\begin{array}{l}\text { Quanti, } 2 \text { estudos seccional (antes e } \\
\text { após a intervenção) } \\
\text { Base comunitária } \\
N=206 \text { UC } \\
\text { Ambos os sexos }\end{array}$ & Uso e compartilhamento de apetrechos & Comportamento de risco sexual \\
\hline $\begin{array}{l}\text { Tl et al. } \\
\text { (2011) } \\
\text { Canadá, Vancouver }\end{array}$ & $\begin{array}{l}\text { Quanti, coorte } \\
\mathrm{N}=503 \cup \mathrm{C} \\
\text { Ambos os sexos }\end{array}$ & $\begin{array}{l}\text { Uso e compartilhamento de apetrechos } \\
\text { Dificuldade de aquisição de apetrechos } \\
\text { como cachimbo } \\
\text { Efeitos da droga: fissura }\end{array}$ & \\
\hline $\begin{array}{l}\text { TOBIN et al. } \\
\text { (2011) } \\
\text { Estados Unidos da } \\
\text { América, Baltimore }\end{array}$ & $\begin{array}{l}\text { Quanti, estudo seccional multicêntrico } \\
\text { Base comunitária } \\
\text { N=230 homens afrodescendentes; } \\
\text { sendo } 84 \text { UC e } 146 \text { não UC; } \\
\text { Prática homossexual nos últimos } 3 \\
\text { meses. } \\
\text { Sexo masculino }\end{array}$ & $\begin{array}{l}\text { Poliusuário (maconha) } \\
\text { Padrão de uso compulsivo }\end{array}$ & $\begin{array}{l}\text { Comprometimento do estado de saúde } \\
\text { Comportamento sexual de risco } \\
\text { Identidade bissexual associada ao crack } \\
\text { Relação com a rede social e sexual; }\end{array}$ \\
\hline $\begin{array}{l}\text { DIAS et al. } \\
\text { (2011) } \\
\text { Brasil, São Paulo }\end{array}$ & $\begin{array}{l}\text { Quanti, coorte } \\
\mathrm{N}=131 \text { UC internados em hospital } \\
\text { geral sendo } \mathrm{N}=107 \text { amostra final } \\
\text { Ambos os sexos }\end{array}$ & $\begin{array}{l}\text { Poliusuário (álcool, cocaína aspirada) } \\
\text { Idade de início de uso: media } 22 \text { anos } \\
\text { Número de pedras consumidas } \\
\text { Padrão de uso compulsivo } \\
\text { Abstinência após } 12 \text { anos de alta } \\
\text { Dependência de crack }\end{array}$ & $\begin{array}{l}\text { Relação com a marginalidade } \\
\text { Maior exposição a situações de violên- } \\
\text { cia (óbito por homicídio) }\end{array}$ \\
\hline $\begin{array}{l}\text { NAPPO; SANCHEZ; } \\
\text { OLIVEIRA } \\
\text { (2011) } \\
\text { Brasil, São Paulo }\end{array}$ & $\begin{array}{l}\text { Quali } \\
\text { N = } 75 \text { mulheres UC > } 14 \text { anos } \\
\text { Adulto jovem (média de } 30 \text { anos) } \\
\text { Sexo feminino }\end{array}$ & $\begin{array}{l}\text { Idade de início de uso: media } 20 \text { anos } \\
\text { Uso e compartilhamento de apetrechos }\end{array}$ & $\begin{array}{l}\text { Baixa escolaridade } \\
\text { Desemprego } \\
\text { Prostituição diariamente com } 4 \text { a } 6 \\
\text { parceiros ao dia } \\
\text { Gravidez e aborto } \\
\text { Maior exposição a situações de violên- } \\
\text { cia Violência física (estupro) } \\
\text { Comprometimento do estado de saúde } \\
\text { Comportamento de risco sexual }\end{array}$ \\
\hline $\begin{array}{l}\text { CHAVES et al. } \\
\text { (2011) } \\
\text { Brasil, São Paulo }\end{array}$ & $\begin{array}{l}\text { Quali } \\
N=40 \text { sendo } 31 \text { UC } \\
N=9 \text { ex UC } \\
>18 \text { anos atendidos na Rede de Saúde } \\
\text { Adultos jovens } \\
\text { Ambos os sexos }\end{array}$ & $\begin{array}{l}\text { Padrão de uso compulsivo } \\
\text { Número de pedras consumidas } \\
\text { Efeitos da droga: fissura em 100\% } \\
\text { Uso coletivo (com amigos) }\end{array}$ & $\begin{array}{l}\text { Baixa renda } \\
\text { Baixa escolaridade } \\
\text { Desemprego } \\
\text { Prostituição } \\
\text { Maior exposição a situações de vio- } \\
\text { lência }\end{array}$ \\
\hline
\end{tabular}


Quadro 1. (cont.)

\begin{tabular}{ll}
\hline HORTA et al. & Quanti; estudo seccional \\
(2011) & $\mathrm{N}=95$ UC atendidos em Caps e \\
Brasil, Porto Alegre & $\begin{array}{l}\text { Capsad } \\
\text { Sexo masculino }\end{array}$ \\
BISCH et al. & Quanti, estudo descritivo retrospectivo \\
(2011) & $\mathrm{N}=40$ jovens entre 16 e 24 anos, \\
Brasil & Entrevistas com UC do Vivavoz (ser- \\
& viço de acolhimento telefônico do \\
& governo federal) \\
& Ambos os sexos
\end{tabular}

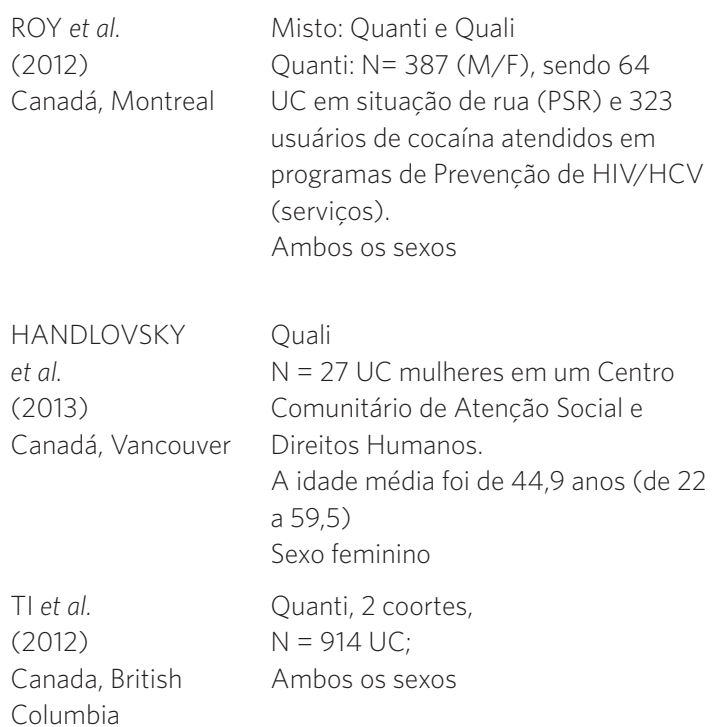

ALVES; ARAÚJO Ensaio Clínico quase experimental; (2012) N=30 UC internados naUnidade de Brasil, Porto Alegre Dependência Química de Hospital Psiquiátrico Média de idade: entre 18 e 50 anos de idade Sexo masculino

PAIM KESSLER Quanti, estudo seccional multicênet al. trico. $\begin{array}{ll}\text { (2012) } & \text { N = 738: sendo } 293 \text { UC, } 126 \text { cocaína } \\ \text { Brasil, Porto Alegre, } & \text { em pó e } 319 \text { outras drogas recruta- }\end{array}$ Rio de Janeiro, São dos em 5 Centros de Tratamento de Paulo e Salvador Drogas

Ambos os sexos

$\begin{array}{ll}\text { KOPETZ et al. } & \text { Quanti, estudo seccional } \\ \text { (2014) } & \mathrm{N}=211 \text { UC em comunidade vulnerável } \\ \text { EUA, Washington } & \text { e em tratamento residencial; } \\ & \text { Ambos os sexos }\end{array}$

Poliusuário (maconha, álcool e nicotina)

Idade de início de uso > 18 anos

Padrão de uso compulsivo

Número de pedras consumidas

Poliusuário (maconha, álcool, tabaco e solventes)

Padrão de uso compulsivo

Consumo diário de crack

Tempo de uso durante a vida (mais de

2 anos)

Número de pedras consumidas

Preferência do uso do crack em relação

à cocaína

Efeitos da droga: efeitos mais rápido,

menos marcas no corpo

Baixo custo de aquisição e maior facilidade na aquisição

Padrão de uso compulsivo ou esporádico Uso e compartilhamento de apetrechos Overdose

Compartilhamento de cachimbos, sendo maior dificuldade de acesso ao cachimbo em mulheres

Poliusuário (álcool, nicotina, cannabis, cocaína em pó)

A idade de início do uso: 14,07 anos Número de pedras de crack consumidas Média de 7 pedras ao dia Efeitos da droga: Fissura e ansiedade
Desemprego/sem ocupação regular Estigma
Contexto familiar como fator protetor Comprometimento do estado de saúde (hepatite, tuberculose, HIV) Relação com a rede de apoio social

Prostituição

Violência (presença policial dificultou acesso a praticas seguras)

Comprometimento do estado de saúde (HIV positivo, lesões bucais, nos dedos e orofaringe)

\section{Desemprego}

Contexto familiar conturbado llegalidade (atividades ilícitas e problemas judiciais)

Maior exposição à situação de violência e agressão física, óbito por homicídio Comprometimento do estado de saúde Comorbidades com transtornos psiquiátricos: > taxa de DPAS em UC.

Baixa renda

Comportamento de risco sexual principalmente em mulheres 
Quadro 1. (cont.)

\begin{tabular}{|c|c|c|c|}
\hline $\begin{array}{l}\text { JORGE } \\
(2013) \\
\text { Brasil, Fortaleza }\end{array}$ & $\begin{array}{l}\text { Quali } \\
N=21 \text { UC } \\
N=15 \text { trabalhadores do Capsad. } \\
\text { Maioria homens, adultos jovens média } \\
32 \text { anos } \\
\text { Ambos os sexos }\end{array}$ & $\begin{array}{l}\text { Poliusuário } \\
\text { Uso precedente de álcool, tabaco, maco- } \\
\text { nha e cocaína em pó } \\
\text { Padrão de uso compulsivo } \\
\text { Busca incessante de prazer } \\
\text { Maconha associado ao crack como redu- } \\
\text { tor da fissura (RD) } \\
\text { Compartilhamento de apetrechos } \\
\text { Consumo em espaços públicos e priva- } \\
\text { dos } \\
\text { Baixo custo de aquisição }\end{array}$ & $\begin{array}{l}\text { Alternativa de consumo para população } \\
\text { de baixa renda associado a maiores } \\
\text { danos de saúde } \\
\text { Relação com a marginalização social } \\
\text { Uso em ambientes inóspitos } \\
\text { Inibição da fome e prejuízo da alimen- } \\
\text { tação } \\
\text { Comprometimento do estado de saúde } \\
\text { com lesões bucais } \\
\text { Maior suscetibilidade a doenças }\end{array}$ \\
\hline $\begin{array}{l}\text { GABATZ et al. } \\
\text { (2013) } \\
\text { Brasil, Rio Grande } \\
\text { do Sul }\end{array}$ & $\begin{array}{l}\text { Quali } \\
N=8 \cup C \text { internados em hospital } \\
\text { geral; } \\
\text { Sexo masculino }\end{array}$ & & $\begin{array}{l}\text { Contexto familiar como fator protetor } \\
\text { ou de risco } \\
\text { Práticas ilícitas } \\
\text { Maior exposição à situação de violência; } \\
\text { Comprometimento do estado de saúde: } \\
\text { Apoio social }\end{array}$ \\
\hline $\begin{array}{l}\text { a) SANTOS CRUZ } \\
\text { et al. ( } 2013 a \text { ) } \\
\text { b) SANTOS CRUZ } \\
\text { et al. ( } 2013 b \text { ) } \\
\text { Brasil, Rio de Janei- } \\
\text { ro e Salvador. }\end{array}$ & $\begin{array}{l}\text { a) Quanti, inquérito, } \\
N=160 \text { UC jovens de } 18 \text { a } 24 \text { anos } \\
\text { base comunitária } \\
\text { b) Quali } \\
\text { Grupo Focal com } 16 \text { jovens UC } \\
\text { Base comunitária } \\
\text { Ambos os sexos }\end{array}$ & Poliusuário & $\begin{array}{l}\text { Relação com a marginalidade social e } \\
\text { ilegalidade } \\
\text { Práticas ilícitas } \\
\text { Comprometimento do estado de saúde } \\
\text { Comportamento sexual de risco }\end{array}$ \\
\hline $\begin{array}{l}\text { KUO et al. } \\
\text { (2014) } \\
\text { Canadá, British } \\
\text { Columbia }\end{array}$ & $\begin{array}{l}\text { Quanti, estudo seccional: clientes de } \\
28 \text { sites de RD } \\
\text { Ambos os sexos }\end{array}$ & $\begin{array}{l}50 \% \text { dos clientes eram UC } \\
\text { Poliusuário } \\
\text { Maconha associado ao crack como redu- } \\
\text { tor da fissura }\end{array}$ & $\begin{array}{l}\text { Alta taxas de PSR (desabrigados) } \\
\text { Relação com a marginalidade social }\end{array}$ \\
\hline $\begin{array}{l}\text { STERK; ELIFSON; } \\
\text { DEPADILLA } \\
\text { (2014) } \\
\text { EUA, Atlanta }\end{array}$ & $\begin{array}{l}\text { Quanti, seccional } \\
N=461 \text { UC afrodescendentes adultos, } \\
\text { Média de idade } 46 \text { anos } \\
\text { Base comunitária } \\
\text { Ambos os sexos }\end{array}$ & $\begin{array}{l}\text { Espaços de consumo: } 55 \% \text { relataram } \\
\text { usar crack somente em casa, ou casa de } \\
\text { parentes e amigos íntimos } \\
\text { Uso individual (14\%) e coletivo } \\
\text { Consumo em dias: menor em domicílio } \\
\text { do que na rua e sozinho ou com amigos } \\
\text { íntimos em relação a conhecidos } \\
\text { Maior consumo quando há envolvimento } \\
\text { com tráfico }\end{array}$ & $\begin{array}{l}\text { PSR } \\
\text { Moradia estável } \\
\text { Prostituição/troca de sexo pela droga } \\
\text { Práticas ilícitas (envolvimento com a } \\
\text { distribuição da droga/tráfico); } \\
\text { Maior exposição a situações de violên- } \\
\text { cia (violência comunitária, desordem } \\
\text { social percebida pela comunidade) }\end{array}$ \\
\hline $\begin{array}{l}\text { URSIN } \\
(2014) \\
\text { Brasil, Salvador }\end{array}$ & $\begin{array}{l}\text { Quali } \\
\text { N =11 UC jovens em situação de rua; } \\
\text { Base comunitária } \\
\text { Sexo masculino }\end{array}$ & & $\begin{array}{l}\text { PSR } \\
\text { Práticas ilícitas }\end{array}$ \\
\hline $\begin{array}{l}\text { ZAVASCHI et al. } \\
\text { (2014) } \\
\text { Brasil, Porto Alegre }\end{array}$ & $\begin{array}{l}\text { Quanti, } \\
N=145 \text { sendo } 56 \text { UC grávidas e } 89 \\
\text { mulheres NUC (não usuários de crack) } \\
\text { em estado puerperal em uma materni- } \\
\text { dade (hospital geral). } \\
\text { Sexo feminino }\end{array}$ & $\begin{array}{l}\text { Metade das gravidas UC relataram uso } \\
\text { de crack na gestação }\end{array}$ & $\begin{array}{l}\text { Baixa renda } \\
\text { Gravidez (quase metade a gravidez foi } \\
\text { planejada) } \\
\text { Contexto familiar frágil (baixo suporte } \\
\text { marital) } \\
\text { Comprometimento do estado de saúde } \\
\text { (HIV, hepatite C, sífilis) } \\
\text { Comorbidades psiquiátricas com DPAS }\end{array}$ \\
\hline $\begin{array}{l}\text { PAULA et al. } \\
\text { (2014) } \\
\text { Brasil, Fortaleza }\end{array}$ & $\begin{array}{l}\text { Quali } \\
N=21 \text { UC e familiares e trabalhadores } \\
\text { em serviço especializado (Capsad) }\end{array}$ & $\begin{array}{l}\text { Padrão de uso compulsivo } \\
\text { Efeitos da droga: fissura }\end{array}$ & $\begin{array}{l}\text { Práticas ilícitas } \\
\text { Contexto familiar (atuando tanto como } \\
\text { fator protetor como de risco) } \\
\text { Maior exposição à situação de violência } \\
\text { (violência familiar) }\end{array}$ \\
\hline
\end{tabular}




\begin{tabular}{|c|c|c|c|}
\hline \multicolumn{4}{|l|}{ Quadro 1. (cont.) } \\
\hline $\begin{array}{l}\text { MOURA et al. } \\
\text { (2014) } \\
\text { Brasil, Porto Alegre, } \\
\text { São Paulo e Sal- } \\
\text { vador }\end{array}$ & $\begin{array}{l}\text { Quanti, estudo seccional, multicên- } \\
\text { trico } \\
N=771 \text { usuários de drogas sendo } 283 \\
\text { UC atendidos em serviços especializa- } \\
\text { dos de saúde } \\
\text { Média de idade } 31 \text { anos } \\
\text { Ambos os sexos }\end{array}$ & Poliusuário (maconha) & Contexto familiar conturbado \\
\hline $\begin{array}{l}\text { CRUZ et al. } \\
\text { (2014) } \\
\text { Brasil, Rio de Ja- } \\
\text { neiro }\end{array}$ & $\begin{array}{l}\text { Quanti, seccional, } \\
\mathrm{N}=111 \text { UC jovens sendo } 81 \text { PSR (fora } \\
\text { de tratamento) e } 30 \text { em tratamento } \\
\text { com programa de internação }\end{array}$ & $\begin{array}{l}\text { Fora de tratamento: compartilhamento } \\
\text { de apetrechos }\end{array}$ & $\begin{array}{l}\text { PSR } \\
\text { Práticas ilícitas } \\
\text { Relação com a marginalidade social } \\
\text { Baixa escolaridade } \\
\text { Sem ocupação regular (maior mendi- } \\
\text { cância nos UC em situação de rua) } \\
\text { Comportamento de risco sexual }\end{array}$ \\
\hline $\begin{array}{l}\text { NARVAEZ et al. } \\
\text { (2014) } \\
\text { Brasil, Pelotas }\end{array}$ & $\begin{array}{l}\text { Quanti, seccional, base populacional; } \\
N=1560 \text { sendo } 2,51 \% \text { UC alguma vez } \\
\text { na vida } \\
\text { Base comunitária; } \\
\text { Jovens entre } 18 \text { e } 24 \text { anos } \\
\text { Maioria homens } \\
\text { Ambos os sexos }\end{array}$ & Poliusuário (cocaína em pó) & $\begin{array}{l}\text { Baixa renda } \\
\text { Práticas ilícitas (porte de arma, envolvi- } \\
\text { mento com tráfico de drogas) } \\
\text { Maior exposição à situação de violência } \\
\text { (Agressão; Violência policial, óbitos por } \\
\text { homicídios) } \\
\text { Mortalidade estimada em } 20 \% \\
\text { Comportamento de risco sexual (uso } \\
\text { menor de preservativos) } \\
\text { Início da vida sexual aos } 14 \text { anos } \\
\text { Comorbidades psiquiátricas (DPAS) }\end{array}$ \\
\hline $\begin{array}{l}\text { BERTONI et al. } \\
\text { (2014) } \\
\text { Brasil, Rio de Janei- } \\
\text { ro e Salvador }\end{array}$ & $\begin{array}{l}\text { Quanti, seccional, } \\
N=159 \text { UC sendo } 124 \text { homens e } 35 \\
\text { mulheres } \\
\text { Base comunitária } \\
\text { Maioria não brancos } \\
\text { Ambos os sexos }\end{array}$ & $\begin{array}{l}\text { Poliusuário (cocaína em pó) } \\
\text { Tempo de uso de crack durante a vida: } 4 \\
\text { anos para sexo M e 4,9 para sexo F } \\
\text { Número de pedras ao dia: } 10 \text { pedras para } \\
\text { homens e } 8 \text { para mulheres. } \\
\text { Uso diário de crack: } 53 \% \text { dos homens } \\
\text { relataram uso diário em relação a } 68 \% \\
\text { das mulheres }\end{array}$ & $\begin{array}{l}\text { PSR/Moradia instável } \\
\text { Baixa escolaridade } \\
\text { Sem ocupação regular/múltiplas fontes } \\
\text { de renda (prostituição, trabalho remu- } \\
\text { nerado, mendicância) } \\
\text { Prostituição maior em mulheres/troca } \\
\text { de sexo por drogas } \\
\text { Maior emprego em homens } \\
\text { Comprometimento do estado de saúde }\end{array}$ \\
\hline $\begin{array}{l}\text { MCNEIL et al. } \\
\text { (2015) } \\
\text { Canadá, British } \\
\text { Columbia }\end{array}$ & $\begin{array}{l}\text { Quali, } \\
N=23 \cup C \\
\text { Idade média de } 40 \text { anos } \\
\text { Base comunitária } \\
\text { Ambos os sexos }\end{array}$ & $\begin{array}{l}\text { Espaços de consumo: na rua, pouco } \\
\text { acesso em espaços de uso seguro (Safe } \\
\text { Smoke Room) } \\
\text { Compartilhamento de apetrechos }\end{array}$ & $\begin{array}{l}\text { PSR } \\
\text { Baixa renda } \\
\text { Maior exposição a violência } \\
\text { Estigma }\end{array}$ \\
\hline $\begin{array}{l}\text { VALDEZ et al. } \\
\text { (2015) } \\
\text { México }\end{array}$ & $\begin{array}{l}\text { Quali, } \\
N=156 \text { UC em situação de rua que } \\
\text { não estão em tratamento } \\
\text { Base comunitária } \\
\text { Maiores de } 18 \text { anos } \\
\text { Maioria homens } \\
\text { Ambos os sexos }\end{array}$ & $\begin{array}{l}\text { Poliusuário } \\
\text { Espaços de consumo: ambiente privado } \\
\text { e público } \\
\text { Padrão de uso compulsivo e uso episó- } \\
\text { dico } \\
\text { Identificado } 4 \text { tipologias de padrão de } \\
\text { consumo: } \\
\text { 1. Dabbler: UC amador/recreativo (oca- } \\
\text { sional, fase inicial, uso em local semipri- } \\
\text { vado) } \\
\text { 2. Stable user: UC estável e esporádico } \\
\text { (ambiente privado, frequência uso inter- } \\
\text { mitente, uso controlado com RD) }\end{array}$ & $\begin{array}{l}\text { PSR } \\
\text { Práticas ilícitas } \\
\text { Sem ocupação regular, trabalho informal } \\
\text { Contexto familiar conturbado ou forta- } \\
\text { lecido } \\
\text { Relação com a rede social } \\
\text { 1. Dabbler: rede social de não usuários; } \\
\text { tem família inserção social } \\
\text { 2. Stable user: trabalho informal, rede } \\
\text { social de UC e não usuários } \\
\text { 3. Piedroso: rede social predominante de } \\
\text { UC e traficantes, uso crônico, envolvi- } \\
\text { mento em atividades ilegais }\end{array}$ \\
\hline
\end{tabular}




\begin{tabular}{|c|c|c|c|}
\hline \multicolumn{4}{|l|}{ Quadro 1. (cont.) } \\
\hline & & $\begin{array}{l}\text { 3. Piedroso: Crack Head - UC crônico ou } \\
\text { compulsivo (ambiente público e semi- } \\
\text { público, uso de longo tempo, comporta- } \\
\text { mentos focados na aquisição da droga) } \\
\text { 4. Old Head: UC de longo tempo (uso } \\
\text { frequente ou episódico, ambiente privado } \\
\text { ou semipúblico) }\end{array}$ & $\begin{array}{l}\text { 4. Old Head: trabalho estável, envol- } \\
\text { vimento com atividades ilícitas, rede } \\
\text { social de UC, poliusuário e alcoolista, } \\
\text { longas histórias de encarceramento, } \\
\text { obrigações sociais mínimas }\end{array}$ \\
\hline $\begin{array}{l}\text { GONÇALVES et al. } \\
\text { (2015) } \\
\text { Brasil, São Paulo }\end{array}$ & $\begin{array}{l}\text { Quali; } \\
N=27 \text { sendo } 20 \text { UC } \\
N=07 \text { profissionais de saúde } \\
\text { Base comunitária } \\
\text { Idade entre } 19 \text { e } 49 \text { anos } \\
\text { Ambos os sexos }\end{array}$ & $\begin{array}{l}\text { Poliusuário (álcool; maconha, êxtase, } \\
\text { cocaína em pó; benzodiazepínicos) } \\
\text { Padrão de uso compulsivo } \\
\text { Efeitos da droga: fissura e paranoia } \\
\text { Maconha como RD: fator protetor e } \\
\text { redução dos efeitos negativos, redução } \\
\text { da quantidade de uso do crack e oferece } \\
\text { menor estigmatização }\end{array}$ & $\begin{array}{l}\text { PSR/moradia instável } \\
\text { Baixa renda } \\
\text { Desemprego } \\
\text { Baixa escolaridade } \\
\text { Contexto familiar com perda familiar } \\
\text { Práticas ilícitas } \\
\text { Maior exposição a situações de violên- } \\
\text { cia (ferimentos físicos) } \\
\text { Estigmatização ('craqueiro') }\end{array}$ \\
\hline $\begin{array}{l}\text { VERNAGLIA; VIEI- } \\
\text { RA; SANTOS CRUZ } \\
\text { (2015) } \\
\text { Brasil, Rio de Ja- } \\
\text { neiro }\end{array}$ & $\begin{array}{l}\text { Quali, } \\
\text { N = } 31 \text { UC em situação de rua } \\
\text { Base comunitária (Manguinhos e } \\
\text { Jacarezinho) } \\
\text { Idade superior a } 18 \text { anos } \\
\text { Ambos os sexos }\end{array}$ & $\begin{array}{l}\text { Padrão de uso compulsivo } \\
\text { Nas mulheres há cuidado responsável } \\
\text { com os filhos enquanto os homens há } \\
\text { desresponsabilização }\end{array}$ & $\begin{array}{l}\text { PSR } \\
\text { Baixa escolaridade } \\
\text { Desemprego e trabalho informal } \\
\text { Maior exposição a situações de violên- } \\
\text { cia (violência no cotidiano, agressão } \\
\text { entre casais) } \\
\text { Prostituição/troca de sexo por droga } \\
\text { Gravidez planejada (a droga não seria } \\
\text { responsável pela gestação) } \\
\text { Sexo seguro com uso de preservativos } \\
\text { Presença de uma rede social com com- } \\
\text { partilhamento de comida e pedra de } \\
\text { crack }\end{array}$ \\
\hline
\end{tabular}

\section{Eixo 1: Características do uso prejudi- cial de crack}

Nesse eixo, serão apresentadas as subcategorias do perfil de consumo dos usuários: poliusuários (entendido uso concomitante de outras SPA); presença de padrão compulsivo; e outras características.

Metade dos estudos citou pessoas poliusuárias, $51 \%$ dos estudos, sendo o crack associado principalmente à maconha, álcool, heroína, cocaína. Cabe destacar que Jorge et al. (2013) observaram predomínio de início do uso da cocaína na forma em pó, migrando para a fumada. Paquette et al. (2010) ressaltam que os jovens que usavam várias substâncias tinham maior risco de iniciar o uso de crack, sendo que, para cada tipo adicional de substância usada, o risco de iniciar o uso de crack aumentou em cerca de $84 \%$. A maconha, ao promover um padrão menos compulsivo, foi citada como droga usada para RD em 4 estudos (GONÇALVES ET AL., 2015; JORGE, 2013; KUO ET AL., 2014; RIBEIRO; SANCHEZ; NAPPO, 2010).

Quanto ao 'padrão de consumo de crack', seu efeito rápido e intenso faz com que a pessoa queira repetir o consumo, levando a um padrão compulsivo e heterogêneo. Quanto à periodicidade, foram relatados usos diário, semanal ou mensal, sendo que 6 estudos descreveram o número de pedras, variando de 1 a 14 pedras/dia (média 10/dia). O uso compulsivo ou exagerado foi denominado por alguns autores como 'padrão binge de consumo' (CHAVES ET AL., 2011; DIAS ET AL., 2011; JORGE, 2013) e foi mencionado em 14 estudos.

Quanto à relação de consumo e custo de aquisição, observou-se que o baixo custo do 
crack e o aumento do preço da cocaína em pó promoveu a disseminação do seu consumo nas camadas sociais economicamente baixas. Em 3 estudos (JORGE, 2013; NAPPO; SANCHEZ; RIBEIRO, 2012; OLIVEIRA; PONCE; NAPPO, 2010), o crack se tornou uma alternativa ao consumo da cocaína em populações mais carentes, vindo a ser uma droga usada por populações mais pobres e marginalizadas; enquanto a cocaína está associada ao uso de pessoas com poder aquisitivo mais elevado e como símbolo de ostentação e poder.

Os efeitos do crack foram destacados em 13 estudos, sendo que $90 \%$ deles demostraram a fissura como efeito principal e 5 associaram outros efeitos, como paranoia, depressão e ansiedade. A fissura por crack tem um papel fundamental no aumento da sua dependência, desencadeando um modo de uso compulsivo. Segundo relato de um usuário, "não existe uma [pedra] só. [...] você nem terminou a primeira [pedra], você já está pensando como você vai fazer para pegar a segunda" (CHAVES ET AL., 2011, P. 1171). Nesses episódios, é comum os usuários passarem dias consumindo apenas crack, álcool e cigarro. A ansiedade em querer fumar crack é tão grande que o indivíduo não consegue ficar parado, pois "o corpo dói, a mente dói, o coração gela, a boca do estômago trava" uma vez que o "corpo pede [...] é uma vontade pior que a fome" (CHAVES ET AL., 2011, P. 1172). Ribeiro, Sanchez e Nappo (2010) também identificaram que, como consequência da fissura, os usuários desenvolvem um padrão de uso obrigatório que envolve muitas vezes envolvimento com situações de alto risco para manter o consumo da droga como comportamento sexual de risco, ferimentos físicos e agressividade aumentada na presença da fissura.

Apenas 2 estudos discutiram a questão da abstinência. Dias et al. (2011) relataram a abstinência em relação a $32 \%$ dos usuários; a composição de um grupo de abstenção apoia a quebra do ceticismo quanto à possibilidade de abandonar o crack e de sustentar sua abstinência ao longo do tempo. Já Bisch et al. (2011) identificaram que jovens UC que usaram mais de 31 pedras por dia não conseguiram abstinência no final do atendimento. Em relação à overdose, apenas 2 estudos relataram a sua ocorrência (HANDLOVSKY ET AL., 2013; RIBEIRO; SANCHEZ; NAPPO, 2010).

Foram identificados espaços de consumo, tanto coletivos quanto individuais, públicos ou privados (ruas, locais públicos para consumo; casa de amigos; própria casa). Observou-se que o fator financeiro influência nos locais de uso. Usuários com melhor poder aquisitivo fazem uso em locais mais protegidos de forma a evitar riscos de agressões e violência.

O compartilhamento de apetrechos para uso de crack foi apontado por 9 estudos, demonstrando um padrão de uso inseguro dos UC, facilitando, por exemplo, a transmissão de HIV/Aids (Síndrome da Imunodeficiência Humana). Três estudos abordaram programas de distribuição de kits de uso seguro nas práticas de consumo de crack como estratégia de $\mathrm{RD}$ ao risco de transmissão de doenças infecciosas (MALCHY ET AL., 2011; ROTHERAM-BORUS ET AL., 2010). Houve uma preocupação com o uso do crack em latas já que o alumínio aquecido pode ocasionar lesão no tecido cutâneo causando o aparecimento de bolhas e feridas na boca e língua e aumentando o risco de contaminação por DST (Doenças Sexualmente Transmissíveis) (JORGE, 2013). Nesse sentido, 6 estudos apontaram o uso em cachimbos como estratégia de RD. Jorge et al. (2013) observaram que a forma de uso mais comum é na lata ou em cachimbos, sendo a substância absorvida de forma mais intensa.

Vale destacar, ainda, o estudo de Valdez et al. (2010) que definiu quatro tipologias de padrão de consumo de crack: 1. Dabbler - UC amador/recreativo (ocasional, fase inicial, uso em local semiprivado); 2. Stable user UC estável e esporádico (ambiente privado, frequência uso intermitente, uso controlado com RD); 3. Piedroso - Crack Head - Usuário crônico ou compulsivo (ambiente público e semipúblico, uso de longo tempo); 4. Old 
Head - Usuários de longo tempo (uso frequente ou episódico; ambiente privado ou semipúblico). Já Medina e Flach (2014) abordaram as formas de uso como funcional e disfuncional; e os modos de consumo como: experimental, eventual, recreativo ou social e dependente; este último quando o uso é incontrolável, compulsivo e intenso, provocando prejuízos para a saúde física, profissional, familiar e social.

\section{Eixo 2: Fatores individuais e sociais associados ao uso de crack}

No que se refere às condições relacionadas com a maior vulnerabilidade pessoal e social, 11 artigos relacionaram o uso de crack à PSR não só no Brasil como em outros países, como o Canadá e EUA. Em um estudo no Canadá, observou-se que a iniciação ao uso de crack parece ser muito comum nessa população, com uma taxa de incidência de 136.6/1.000. No estudo de Paquette (2010), a taxa é ainda maior quando a análise se limita aos jovens que iniciaram o uso de drogas por uma nova via de administração de cocaína, com 205,8 casos/1.000.

Outro fator contextual importante associado aos UC é o desemprego ou a falta de uma ocupação regular. Segundo Ribeiro, Sanchez e Nappo (2010), os UC ficam muitas vezes desempregados após alguns meses do uso de droga. Isso geralmente ocorre porque o usuário perde o interesse pelo trabalho ou não consegue mais obedecer às regras.

Quanto às fontes de renda dos UC, foram identificadas: o trabalho sexual, a prostituição e a mendicância. Ribeiro, Sanchez e Nappo (2010) identificaram a prostituição como a modalidade mais frequente usada pelas mulheres para a obtenção da droga, com risco iminente de infecção por DST/ Aids.

Além das características pessoais, é plausível presumir que fatores externos, como o mercado de drogas e a rede social, podem influenciar nas escolhas que os jovens fazem em relação ao consumo de SPA. O envolvimento dos UC com atividades ilícitas, como pequenos delitos, furtos e envolvimento com tráfico de drogas, foi outro fator social relatado nos estudos. Oliveira, Ponce e Nappo (2010) ressaltam que práticas de delitos podem estar relacionados com a fissura que o crack provoca. Outro fator relacionado com a ilegalidade foi a busca constante de dinheiro para a aquisição do crack e a marginalização social descrita em 8 estudos. Alguns deles realizados em comunidades vulneráveis, no Rio de Janeiro (SANTOS CRUZ ET AL., 2013A, 2013B), observaram que os comportamentos de riscos dos UC estão associados a pessoas economicamente marginalizadas, como a PSR. Essa relação foi vista, também, em estudo recente no Canadá, que mostrou que os UC estão entre os mais marginalizados socialmente, associados à alta taxa de desabrigados e à poliusuários, sendo o crack o mais prevalente; e a problemas de saúde como infecções por HIV (KUO ET AL., 2014).

O óbito por homicídio também foi a causa mais prevalente das mortes de UC segundo 3 estudos. Dias et al. (2011), em um estudo com UC após 12 anos de alta hospitalar, encontraram 27 ex-usuários que já haviam falecido em 107; dos que haviam falecido, $59 \%$ morreram de forma violenta, sendo a Aids a segunda maior causa de morte.

O estudo de Chaves et al. (2011) também ajuda a explicar o envolvimento do UC com atividades ilícitas, relatando que, uma vez que o crack adquiriu lugar de extrema importância na vida do indivíduo, a urgência em consumi-lo muda, muitas vezes, os valores que até então norteavam sua conduta, levando-o a realizar atividades que colocam em risco a sua integridade moral e física; pois o que está em foco é o uso de mais crack. Para a pessoa em fissura, perder a família, gastar altas quantias, descuidar do próprio corpo não parece tão ruim quanto não usar crack. Ursin (2014), em seu estudo em cenas de uso em Salvador, ressalta que o crack, como substância, aparece como um 
mediador dando coragem para roubar; mas homicídios podem ou não ocorrer.

A busca obcecada pela droga suscita comportamentos de risco que comprometem a saúde do indivíduo e suas relações sociais. Observou-se que o uso da droga pode levar a delitos, tais como furtos e outras atividades que ajudem a consegui-la (GABATZ ET AL., 2013). Mais um aspecto relacionado com a ilegalidade foi a presença do tráfico de drogas na rede de relações dos UC (RIBEIRO; SANCHEZ; NAPPO, 2010). Esses riscos são associados, principalmente, com a violência na 'boca' (lugar da venda da droga) causada por confronto com a polícia.

Kopetz (2014) encontrou resultados que sugerem que a experiência da exclusão social também pode ser um fator de risco importante relacionado com práticas de sexo inseguro, estando as mulheres mais vulneráveis.

Um outro aspecto social relevante é a estigmatização dos UC. O estigma envolvendo o uso de crack é bem maior que com outras drogas, devido a algumas características, como: morar na rua, usar a droga em grandes conglomerados de pessoas, estar muitas vezes sujo, com imagem associada a de um 'zumbi'. Ursin (2014) chama a atenção para a necessidade de desenvolver uma menor estigmatização, por meio de um debate público sobre o consumo de crack.

Outro fator social associado ao consumo de drogas foi o contexto familiar; considerado tanto como fator protetor (PAULA ET AL., 2014; HANDLOVSKY ET AL., 2013) quanto como fator de risco, quando o relacionamento familiar é problemático (GONÇALVES ET AL., 2015; PAIM KESSLER ET AL., 2012; PAQUETTE ET AL., 2010). No estudo de Paquette et al. (2010), as pessoas que têm, no seu contexto familiar, um parente com problema de uso de SPA reduziram o risco da iniciação do crack em quase $50 \%$.

Os trabalhadores de um serviço de saúde mental também associaram o uso do crack às relações familiares difíceis e pontuaram que a família é a principal motivadora das recaídas (PAULA ET AL., 2014).
O estudo de Sterk, Elifson e Depadilla (2014) mostrou que o ambiente de desordem social percebida foi um preditor significativo para o número de dias de uso do crack. O envolvimento com distribuição de drogas e com o sexo também foi associado ao aumento do número de dias. A situação de gravidez e abortos em UC foi relatada em 3 estudos. Zavaschi et al. (2014) observaram que um grande número de UC tiveram um maior número de gestações e de partos prematuros e um QI (Quoeficiente de Inteligência) mais baixo do que as não usuárias de crack. Essas UC pertenciam a uma classe social mais baixa, com etnia não branca e com frequência de uso de álcool e tabaco durante a gestação. É relevante dizer-se que 75\% das UC não tiveram assistência pré-natal, por isso, apenas $25 \%$ informaram ter doenças infecciosas. $42 \%$ tiveram alguma infecção diagnosticada como HIV, hepatite $\mathrm{C}$ ou sífilis. Outro resultado encontrado foi que os bebês de mães UC pesavam significativamente menos do que o grupo de não usuárias. $\mathrm{O}$ estudo observou, ainda, que $47 \%$ relataram que a gestação foi planejada, o que levou os autores a indagar se isso poderia ser um resultado da dificuldade em fazer planos realistas na tentativa de recuperar a perda de outros filhos, já que a maioria dos bebes não ficaram com suas mães.

É esperado que os danos sociais e de saúde atinjam, de forma mais intensa, os grupos com maior vulnerabilidade (JORGE ET AL., 2013). Assim, os estudos apontaram para um aumento nos fatores de risco e comprometimento no estado de saúde devido ao uso de crack relacionado com o comportamento de risco sexual. O relato de sexo inseguro foi descrito em 12 estudos.

Tobin et al. (2011), em sua pesquisa comparando as características da rede social e sexual de UC e de não usuários nos EUA, observaram que a rede sexual dos não usuários tinha um número muito maior de parceiros que usavam preservativos do que a rede de UC sendo, portanto, o uso de crack associado 
ao aumento de risco sexual por práticas sexuais sem preservativos. Constataram, ainda, que a rede sexual dos UC é diversificada e que consiste de pessoas de ambos os sexos, levando a uma forte associação dos UC com a identidade bissexual e que $91 \%$ dos UC tiveram resultado positivo para HIV (TOBIN ET AL., 2011). O crack também foi associado ao comportamento de risco sexual, em estudo recente realizado no sul do Brasil, no qual foi demostrado que os UC têm maior probabilidade de não usar preservativos, apresentando, por isso, alto índice de comportamento sexual de risco com transmissão de HiV (narvaez et al., 2014). Corroborando esses achados, o estudo de Debeck et al. (2009), com UC que usam também drogas injetáveis, demonstrou que os fumantes diários de crack apresentam maior risco de soroconversão do HIV associado a comportamentos sexuais, bem como ao uso do crack em recipientes de vidros ou metal, que produzem ferimentos na boca e fazem com que esses usuários se tornem mais vulneráveis à transmissão do HIV. No Canadá, observou-se um grande aumento no uso de crack em Vancouver entre os usuários de drogas injetáveis em situação de rua (WERB ET AL., 2010).

Três estudos abordaram a relação do UC com transtornos psiquiátricos, relacionando os UC com a Desordem de Personalidade Antissocial (DPAS) que pode afetar o resultado dos tratamentos. Observaram, também, que UC são mais marginalizados economicamente e apresentam comportamento sexual de risco com comprometimento em seu estado de saúde. Outro resultado importante foi a baixa utilização dos serviços sociais e de saúde de UC. Essa baixa utilização pode estar associada às dificuldades de acesso a esses serviços devido tanto à distância por causa de meios de transporte quanto ao horário de funcionamento desses serviços e ao estigma dos UC pelos profissionais de saúde (PAIM KESSLER ET AL., 2012; STERK; ELIFSON; DEPADILLA, 2014; ZAVASCHI ET AL., 2014).

\section{Discussão}

Em síntese, os estudos apontam para um uso do crack mais próximo do padrão compulsivo, associado à vulnerabilidade social, embora existam relatos de uso eventual e recreativo, contrariando a divulgação na mídia de que o crack é extremamente viciante e leva a morte em pouco tempo.

Observou-se, ainda, que os fatores sociais e contextuais associados ao uso de crack estão relacionados com a maior exposição a situações de violência, marginalização, gravidez, de estar em situação de rua e a estar mais expostos a fatores de risco para a saúde, como comportamento de sexo inseguro, compartilhamento de apetrechos para uso de crack e um grande número de parceiros sexuais que levam a uma maior exposição às doenças infectocontagiosas, principalmente o HIV.

Ao se considerar que a maioria dos estudos adotaram mais métodos quantitativos e menos de pesquisa social, houve evidências relevantes quanto à dimensão epidemiológica e clínica dos padrões de consumo, persistindo, ainda, lacunas no conhecimento em torno das políticas públicas sobre drogas, suas motivações políticas e seus modelos de intervenção. Por isso, talvez seja necessário investigações por parte de outros campos além da saúde pública, como a ciência política, a economia e o direito.

O cuidado aos UC e outras drogas, histórico pela área social e pela segurança pública, vem sendo marcado pela baixa integração com outros setores como o do trabalho, da educação e da saúde. Apesar da crescente assumpção do uso de drogas como um importante problema de saúde pública e da não criminalização do usuário, as políticas de atenção à saúde ao UC têm-se mostrado ainda de baixa cobertura, com barreiras de acesso a esses usuários.

Há que se pensar novos modelos de atenção, que considerem a complexidade e vulnerabilidade do cuidado a usuários de drogas, em especial aos do crack, haja vista 
sua relação com PSR, com morbimortalidade elevada por agravos de diferentes naturezas, com violência e exposição a fatores individuais, ambientais e sociais de risco para a vida e saúde. Além disso, a ocorrência de problemas com a polícia ou a justiça; o desemprego; o envolvimento em situações de violência traduzem problemas importantes associados ao uso do crack, o que gera necessidades de ações intersetoriais.

No Brasil, a pesquisa nacional sobre o perfil dos UC (BASTOS; BERTONI, 2014) identificou um perfil de extrema vulnerabilidade social e exclusão, necessitando-se ações de saúde abrangentes, integrais e intersetoriais, como oferta de banho, alimentação e apoio para completar a educação e conseguir trabalho.

As políticas e práticas devem seguir na luta da 'contrafissura', conceito de Lancetti (2015) que aborda a discussão do tema das drogas como parte do "conjunto-droga: produção-comercialização-judicialização-repressão-cuidado-terapêuticas-exposição midiática" (LANCETTI, 2015, P. 15).

A questão do crack e outras drogas torna-se, a cada dia, mais complexa ao envolver os meios biológico, social, psicológico e cultural das pessoas em seu uso prejudicial. Questões como desemprego, pessoas vivendo em situação de rua e desigualdade social geram um novo cenário de vulnerabilidades que precisam ser levadas em consideração na abordagem aos usuários de drogas (ZANOTTO; BUCHELE, 2013).

A compreensão dos padrões de uso, como a compulsão e a fissura gerada pelo uso do crack, é importante no delineamento de ações de controle do consumo. A existência do controle da fissura sugere que o fenômeno do uso de crack ultrapassa seus efeitos farmacológicos e é influenciado por questões sociais, ambientais e emocionais. Essas questões poderiam ser mais bem exploradas pelos profissionais que atuam com atendimento a usuários de drogas e com elaboração de políticas públicas sobre o tema (CHAVES ET AL., 2011).

No âmbito do tratamento ou das estratégias de intervenção, várias medidas são importantes. Horta et al. (2011) e Jorge (2013) recomendam como iniciativa redutora de riscos e danos facilitar o acesso de usuários de crack aos serviços do Sistema Único de Saúde. Pessoas com maior comprometimento social parecem não chegar às redes de saúde, o que remete à necessidade de os municípios implementarem estratégias de facilitação do acesso, com maior envolvimento de agentes comunitários de saúde; com os Programas de Redução de Danos (PRD) ou com os Consultórios na Rua, ou outras ações de aproximação entre comunidade e serviços. Estratégias promissoras no âmbito da saúde pública de $\mathrm{RD}$, como a distribuição de apetrechos para uso seguro de crack; provisão de espaços públicos para uso supervisionado de drogas e ações educativas e de promoção de saúde estreitando o contato dos profissionais de saúde com os UC, podem ajudar a promover uma menor estigmatização (DEBECK ET AL., 2009; PAQUETTE ET AL., 2010; MALCHY ET AL., 2011; URSIN, 2014).

Os formuladores de políticas públicas brasileiras deveriam priorizar as iniciativas que promovam mudança social e ativem a cidadania, com estratégias de RD que necessitam continuar em destaque na agenda política.

Como limitações do presente estudo, pode-se destacar o tempo que ficou limitado aos últimos seis anos e a não utilização de teses, escolhas já explicitadas na seção de metodologia. Justifica-se, ainda, a não realização de análises estatísticas e a adoção de critérios quantitativos para a avaliação da qualidade dos artigos, considerando-se tratar aqui de revisão exploratória da literatura o máximo possível inclusiva, diante da complexidade do tema estudado e de sua aplicação para políticas públicas.

\section{Considerações finais}

A abordagem ao uso de drogas, em especial ao crack, deve estar focada na perspectiva 
da $\mathrm{RD}$, um modelo de saúde que defende a vida, a autonomia, os direitos e o respeito as pessoas, e não na utopia de eliminação do consumo, produção e comercialização de drogas, como advogam defensores de políticas de 'Guerra às Drogas' e o proibicionismo (MEDINA; NERY FILHO; FLACH, 2014).

Considera-se que coexistem diferentes abordagens que norteiam as pesquisas e as práticas com os usuários de drogas, são elas: 1. 'Guerra às Drogas' ou modelo moral/criminal, que tem como objetivo maior o combate ao tráfico de drogas e a criminalização dos usuários e de traficantes, visando um mundo livre de drogas. Está associado a um discurso antidrogas, fruto de vários tratados internacionais que tem como compromisso a prevenção do consumo e a repressão da produção e oferta (MARLATT, 1999). 2. O modelo da doença (MARLATT, 1999), no qual o uso de drogas é avaliado como um ato moral, em que a abstinência é o objetivo final. Nesse modelo, o tratamento dos usuários de drogas tem a internação ou o isolamento com objetivos para impedir o acesso dos usuários à SPA visando interromper o uso. Aqui, o uso abusivo de drogas é tratado como dependência química, como uma doença crônica com indicação de internação hospitalar, visando à estabilização do quadro (DIAS ET AL., 2011; RIBEIRO; LARANJEIRA, 2010). 3. O modelo de atenção psicossocial que oferta um cuidado de base comunitária no território e é centrado no discurso do respeito às diferenças, à defesa da vida, ao direito à liberdade e à dignidade da pessoa humana, cujo objetivo é a inclusão social ou reinserção social, que se contrapõe às práticas de recolhimento dos usuários de drogas em abrigos à internação compulsória. Esse modelo tem como principal dispositivo institucional a rede de atenção psicossocial constituída por dispositivos abertos de natureza territorial e comunitária (AMARANTE, 2007; BOKANY, 2015). 4. A abordagem da $\mathrm{RD}$, que se direciona à oferta de cuidados que minimizem as consequências adversas do uso prejudicial de drogas, tanto para o indivíduo quanto para a sociedade. A terapêutica pautada na RD é considerada de 'baixa exigência' por não exigir dos usuários a abstinência como um requisito obrigatório, tornando-se uma estratégia desenvolvida também para pessoas que não desejam ou não conseguem diminuir/cessar o uso de drogas, bem como para os demais usuários com dificuldade para acessar serviços de saúde ou aderir ao cuidado integral à saúde (HART, 2014; LANCETTI, 2015; PASSOS; SOUZA, 2011). 5. Por último, têm-se o debate da descriminalização e da legalização das drogas, que compreende que o uso delas não deve ser considerado crime; assim, ao usuário deve ser ofertado tratamento e cuidado, e não reclusão em ambiente prisional (BOTTINI, 2015).

O compromisso dos profissionais e gestores da saúde é promover acesso a um cuidado integral nos moldes da atenção psicossocial e da RD. Para isso, é necessário investir-se em estratégias de cuidado emancipadoras, que incluam informação clara proporcionando autonomia aos usuários. Para pessoas que optem pelo uso de drogas, há estratégias de $\mathrm{RD}$ na saúde pública, que minimizam os danos à saúde e à vida.

Como contribuição para a formulação de políticas e ações de saúde pública no Brasil, pode-se concluir que o foco das ações e estratégias de intervenção não podem ter como finalidade exclusiva e principal a missão de reduzir o número de usuários dependentes e com problemas decorrentes do uso de drogas, mas sim de investir em políticas públicas que priorizem o acesso e a qualidade da atenção integral, com práticas de promoção da saúde, no âmbito de uma rede de saúde humanizada e integrada a outras ações intersetoriais, cujo objetivo principal seja a defesa da vida e da cidadania das pessoas. 


\section{Referências}

ALVES, G. S. L.; ARAUJO, R. B. The use of cooperative games to treat crack-dependent patients hospitalized at a detoxication unit. Rev Bras Med Esporte, São Paulo, v. 18, n. 2, p. 77-80, 2012.

AMARANTE, P. Saúde Mental e Atenção Psicossocial. 20. ed. Rio de Janeiro: Fiocruz, 2007.

AYRES, J. R. C. M. Práticas educativas e prevenção de HIV/Aids: lições aprendidas e desafios atuais. Interface (Botucatu), Botucatu, v. 6, n. 11, p. 11-24, ago. 2002.

AYRES, R. et al. O conceito de vulnerabilidade e as práticas de saúde: novas perspectivas e desafios. In: Promoção da saúde: conceitos, reflexões, tendências. Rio de Janeiro: Fiocruz, 2005. p. 117-140.

BASTOS, F. I.; BERTONI, N. Pesquisa Nacional sobre o uso de crack: quem são os usuários de crack e/ou similares do Brasil? Quantos são nas capitais brasileiras? Rio de Janeiro: Icict; Fiocruz, 2014.

BERTONI, N. et al. Exploring sex differences in drug use, health and service use characteristics among young urban crack users in Brazil. Int. J. Equity Health, Londres, v. 13, 2014.

BISCH, N. K. et al. Aconselhamento telefônico para jovens usuários de crack. Rev. Gaúcha Enferm., Porto Alegre, v. 32, n. 1, p. 31-39, mar. 2011.

BOKANY, V. Drogas no Brasil: entre a saúde e a justiça: proximidades e opiniões. São Paulo: Fundação Perseu Abramo, 2015

BOTTINI, P. C. Crime de porte de drogas para uso próprio e o Supremo Tribunal Federal. Rio de Janeiro: Viva Rio, 2015.

BRASIL. Ministério da Justiça. O uso de substâncias psicoativas no Brasil: módulo 1. 7. ed. Brasília, DF: Secretaria Nacional de Políticas sobre Drogas, 2014.

Presidência da República. Decreto no 7.179

Brasil. Decreto no 7.179, de 20 de maio de 2010. Institui o Plano Integrado de Enfrentamento ao Crack e outras Drogas. Diário Oficial [da] União, Brasília, DF, 2010. Disponível em: <https://www.planalto.gov.br/ ccivil_03/_ato2007-2010/2010/decreto/d7179.htm>. Acesso em: 1 nov. 2016

CHAVES, T. V. et al. Fissura por crack: comportamentos e estratégias de controle de usuários e ex-usuários. Rev. Saúde Pública, São Paulo, v. 45, n. 6, p. 1168-1175, dez. 2011.

CRUZ, M. et al. Comparing key characteristics of young adult crack users in and out-of-treatment in Rio de Janeiro, Brazil. Subst Abuse Treat Prev Policy v. 9, 2014. Disponível em: <http://www.readcube.com/ articles/10.1186/1747-597x-9-2>. Acesso em: 10 abr. 2017.

DEBECK, K. et al. Smoking of crack cocaine as a risk factor for HIV infection among people who use injection drugs. CMAJ, Quebec, v. 181, n. 9, p. 585-589, out. 2009.

DIAS, A. C. et al. Mortality rate among crack/cocaine-dependent patients: a 12-year prospective cohort study conducted in Brazil (clinical report). Journal of Substance Abuse Treatment, Nova York, v. 41, n. 3, p. 273, 2011.

ESCOHOTADO, A. A História de las drogas. Madri: Alianza Editorial, 1996.

FISCHER, B. et al. Social, health and drug use characteristics of primary crack users in three mid-sized communities in British Columbia, Canada. Drug-Educ. Prev. Policy, Londres, v. 17, n. 4, p. 333-353, 2010.

FIORE, M. Uso de drogas: substâncias, sujeitos e eventos. Campinas: Unicamp, 2013.

GABATZ, R. I. B. et al. Percepção do usuário sobre a droga em sua vida. Esc. Anna Nery, Rio de Janeiro, v. 17, n. 3 , p. $520-525,2013$

GONÇALVES, V. M. et al. Following up crack users 
after hospital discharge using record linkage methodology: an alternative to find hidden populations. BioMed Research International, Nova York, v. 2015, p. 1-5, 2015.

HANDLOVSKY, I. E. et al. The process of safer crack use among women in Vancouver's Downtown Eastside. Qual Health Res., Toronto, v. 23, n. 4, p. 450-462, abr. 2013.

HART, C. Um Preço Muito Alto: a jornada de um neurocientista que desafia nossa visão sobre as drogas. Rio de Janeiro: Zahar, 2014.

HORTA, R. et al. Crack cocaine users who attend outpatient services. Cad. Saude Publica, Rio de Janeiro, v. 27, n. 11, p. 2262-2269, 2011.

IVSINS, A. et al. Uptake, benefits of and barriers to safer crack use kit (SCUK) distribution programmes in Victoria, Canada-A qualitative exploration. Int. J. Drug Policy, Nova York, v. 22, n. 4, p. 292-300, 2011.

JORGE, M. Ritual de consumo de crack: aspectos socioantropológicos repercussões para a saude do usuário. Ciênc. Saúde Coletiva, Rio de Janeiro, v. 18, n. 10, p. 2909-2918, out. 2013.

KOPETZ, C. et al. Gender and social rejection as risk factors for engaging in risky sexual behavior among crack/cocaine users. Prev. Sci., Nova York, v. 15, n. 3, p. 376-384, 2014.

KUO, M. et al. A drug use survey among clients of harm reduction sites across British Columbia, Canada, 2012. Harm reduction journal, Quebec, v. 11, n. 13, 2014.

LANCETTI, A. Contrafissura e plasticidade psíquica. São Paulo: Hucitec, 2015.

MALCHY, L. A. et al. Do crack smoking practices change with the introduction of safer crack kits? Can $J$ Public Health, Quebec, v. 102, n. 3, p. 188-192, 2011.

MARLATT, G. A. Redução de danos no mundo: uma breve história. In: Redução de danos: estratégias práticas para lidar com comportamentos de alto risco. Porto Alegre: Artmed, 1999.
MCNEIL, R. et al. "We need somewhere to smoke crack": an ethnographic study of an unsanctioned safer smoking room in Vancouver, Canada. International Journal of Drug Policy, Nova York, v. 26, n. 7, p. 645-652, 2015 .

MEDINA, M. G.; FLACH, P. M. V. Políticas de Prevenção e Cuidado ao Uusário de Substâncias Psicoativas (SPA). In: PAIM, J. S.; ALMEIDA-FILHO, N. Saúde Coletiva: teoria e prática. Rio de Janeiro: MedBook, 2014. p. 479-500.

MEDINA, M. G.; NERY FILHO, A.; FLACH, P. M. V. Políticas de Prevenção e cuidado ao usuário de substâncias psicoativas. In: PAIM, J. S.; ALMEIDA-FILHO, N. Saúde Coletiva: teoria e prática. Rio de Janeiro: MedBook, 2014. p. 479-500.

MOURA, H. et al. Crack/cocaine users show more family problems than other substance users. Clinics, São Paulo, v. 69, n. 7, p. 497-499, 2014.

NAPPO, S. A.; SANCHEZ, Z. M.; RIBEIRO, L. A. Há uma epidemia de crack entre estudantes no Brasil? Comentários sobre aspectos da mídia e da saúde pública. Cad. Saúde Pública, Rio de Janeiro, v. 28, n. 9, p. 1643-1649, set. 2012.

NAPPO, S.; SANCHEZ, Z.; OLIVEIRA, L. Crack, AIDS, and women in Sao Paulo, Brazil. Subst. Use Misuse, Nova York, v. 46, n. 4, p. 476-485, 2011.

NARVAEZ, J. C. M. et al. Violent and sexual behaviors and lifetime use of crack cocaine: A population-based study in Brazil. Soc Psychiatry Psychiatr Epidemiol, Berlin, v. 49, n. 8, p. 1249-1255, 2014.

OLIVEIRA, L. G.; PONCE, J. D. C.; NAPPO, S. A. Crack cocaine use in Barcelona: a reason of worry. Subst. Use Misuse, Nova York, v. 45, n. 13, 2010.

\section{PAIM KESSLER, F. H. et al. Crack Users Show High} Rates of Antisocial Personality Disorder, Engagement in Illegal Activities and Other Psychosocial Problems. American Journal on Addictions, Washington, v. 21, n. 4, p. 370-380, 2012. 
PAQUETTE, C. et al. Predictors of crack cocaine initiation among Montréal street youth: A first look at the phenomenon. Drug and Alcohol Dependence, Dublin, v. 110, n. 1, p. 85-91, 2010.

PASSOS, E. H.; SOUZA, T. P. Redução de danos e saúde pública: construções alternativas à política global de "guerra às drogas". Psicol. Soc., Florianópolis, v. 23, n. 1, p. 154-162, abr. 2011.

PAULA, M. et al. Crack users in treatment: experiences, meanings and senses. Saúde Soc., São Paulo, v. 23, n. 1, p. 87-98, jan./mar. 2014.

RIBEIRO, L.; SANCHEZ, Z.; NAPPO, S. Surviving crack: a qualitative study of the strategies and tactics developed by Brazilian users to deal with the risks associated with the drug. BMC Public Health, Londres, v. 10, 2010.

RIBEIRO, M.; LARANJEIRA, R. O tratamento de usuário de crack: avaliação clínica, psicossocial, neuropsicológica e de risco. São Paulo: Casa Leitura Médica, 2010.

ROTHERAM-BORUS, M. et al. Reducing HIV risks among active injection drug and crack users: the safety counts program. AIDS behav., Nova York, v. 14, n. 3, p. 658-668, 2010.

ROY, E. et al. Drug use patterns in the presence of crack in downtown Montréal. Drug and Alcohol Review, Sydney, v. 31, n. 1, p. 72-80, 2012.

SAMPAIO, R. F.; MANCINI, M. C. Systematic review studies: a guide for careful synthesis of the scientific evidence. Braz J Phys Ther, São Carlos, v. 11, n. 1, p. 83-89, 2007.

SANTOS CRUZ, M. et al. Key drug use, health and socio-economic characteristics of young crack users in two Brazilian cities. Int J Drug Policy, Liverpool, v. 24, n. 5 , p. 432-438, 2013a.

SANTOS CRUZ, M. et al. Patterns, determinants and barriers of health and social service utilization among young urban crack users in Brazil, BMC Health Services Research, Londres, v. 13, p. 536, 2013 b.
SHEA, B. J. et al. Development of AMSTAR: a measurement tool to assess the methodological quality of systematic reviews. BMC Medical Research Methodology, Londres, v. 7, n. 1, dez. 2007.

SODELLI, M. Drogas, prevenção e as ações redutoras de vulnerabilidades. In: BOKANY, V. (Org.). Drogas no Brasil: entre a saúde e a justiça: proximidades e opiniões. São Paulo: Fundação Perseu Abramo, 2015. p. 223-235.

STERK, C.; ELIFSON, K.; DEPADILLA, L. Neighbourhood structural characteristics and crack cocaine use: Exploring the impact of perceived neighbourhood disorder on use among African Americans. Int J Drug Policy, Liverpool, v. 25, n. 3, p. 616-623, 2014.

TI, L. et al. Difficulty accessing crack pipes and crack pipe sharing among people who use drugs in Vancouver, Canada (report). Substance Abuse Treatment, Prevention, and Policy, Londres, v. 6, p. 34, 2011.

TI, L. et al. Factors associated with difficulty accessing crack cocaine pipes in a Canadian setting (report). Drug and Alcohol Review, Sydney, n. 7, 2012.

TOBIN, K. E. et al. A Comparison of the social and sexual networks of crack-using and non-crack using african american men who have sex with men. $J$ Urban Health, Carolina do Norte, v. 88, n. 6, p. 1052, 2011.

\section{UNITED NATIONS OFFICE ON DRUGS AND CRIME} (UNODC). World Drug Report. Viena: OMS, 2015.

URSIN, M. "Crack ends it all?" A study of the interrelations between crack cocaine, social environments, social relations, crime, and homicide among poor, young men in urban Brazil. Contemp Drug Probl, Nova York, v. 41, n. 2, p. 171-199, 2014.

VALDEZ, A. et al. Emerging patterns of crack use in Mexico City. Int J Drug Policy, Liverpool, v. 26, n. 8, p. $739-745,2015$

VALDEZ, A. et al. Fumando la piedra: emerging patterns of crack use among latino immigrant day laborers 
in New Orleans. $J$ Immigr Minor Health, Nova York, v. 12, n. 5, p. 737-742, 2010.

VERNAGLIA, T. V. C.; VIEIRA, R. A. M. S.; CRUZ, M. S. Crack cocaine users living on the streets - gender characteristics. Ciência \&t Saúde Coletiva, Rio de Janeiro, v. 20, n. 6, p. 1851, 2015.

WERB, D. et al. Modelling crack cocaine use trends over 10 years in a Canadian setting. Drug Alcohol Rev, Oxfordshire, v. 29, n. 3, p. 271-277, 2010.

ZANOTTO, D.; BUCHELE, F. Revisão sistemática sobre crack: aspectos relacionados ao uso e abuso. Saúde debate, Rio de Janeiro, v. 37, n. esp., p. 12-20, dez. 2013.

ZAVASCHI, M. L. S. et al. Socio-demographic and clinical characteristics of pregnant and puerperal crackcocaine using women: Preliminary data. Revista de Psiquiatria Clínica, São Paulo, v. 41, n. 5, p. 121-123, 2014

ZINBERG. Drug, set and setting. Connecticut: Yale University, 1984.

Recebido para publicação em agosto de 2016

Versão final em outubro de 2016

Conflito de interesses: inexistente

Financiamento: não houve 